\title{
Estrutura da comunidade arbórea de fragmentos de floresta estacional semidecidual na bacia hidrográfica do rio São Domingos, Rio de Janeiro, Brasil
}

\author{
Tree community structure of fragments of semideciduous seasonal forest \\ in the São Domingos river basin, Rio de Janeiro, Brazil
}

\author{
Maurício Lima Dan ${ }^{1}$, João Marcelo Alvarenga Braga ${ }^{2}$ \& Marcelo Trindade Nascimento ${ }^{3}$
}

\begin{abstract}
Resumo
Pouco se conhece sobre a estrutura e composição florística das florestas do noroeste fluminense, intensamente fragmentadas. Assim, o presente estudo objetivou contribuir para o conhecimento da flora arbórea desta região respondendo as seguintes questões: Qual a composição florística dos fragmentos e que espécies os caracterizam? A comunidade arbórea dos fragmentos da Bacia Hidrográfica do Rio São Domingos (BHRSD) possui elevada riqueza e diversidade florística? Em que estádio sucessional se encontram os fragmentos florestais da BHRSD? Foram selecionados quatro fragmentos florestais. Em cada um dos fragmentos foram instaladas cinco parcelas de $20 \mathrm{~m} \times 20 \mathrm{~m}$. Todos os indivíduos vivos e mortos com DAP $\geq 5 \mathrm{~cm}$ foram amostrados. Um total de 198 táxons pertencentes a 52 famílias botânicas foi amostrado. As espécies mais abundantes foram Apuleia leiocarpa, Gallesia integrifolia, Dalbergia nigra e Guarea guidonia. Os valores de riqueza e de diversidade ( $\left.\mathrm{H}^{\prime}\right)$ de espécies nas cinco diferentes áreas amostrais (0,2 ha) variaram de 33 a 89 e 2,81 a 3,87. Os fragmentos, apesar de secundários e em estádio intermediário de sucessão, apresentaram elevada diversidade, riqueza e uma composição peculiar de espécies arbóreas, que parece receber influências florísticas de formações florestais ombrófilas e semidecíduas do sudeste brasileiro. Sugere-se que estas referidas características estejam relacionadas à posição geográfica da região.
\end{abstract}

Palavras-chave: composição florística, diversidade arbórea, fragmentação florestal, noroeste fluminense.

\begin{abstract}
Little is known about the structure and floristic composition of the highly fragmented northwestern Rio de Janeiro forests. Thus, this study aimed to address the following questions: What is the floristic composition and which species characterize it? Does the tree community show high species richness and diversity? What are the successional stages? Four fragments were selected. Five $20 \mathrm{~m} \times 20 \mathrm{~m}$ plots were allocated in each fragment and all dead and alive trees $\geq 5 \mathrm{~cm}$ DBH were sampled. A total of 198 taxa belonging to 52 families was sampled. The most important species were Apuleia leiocarpa, Gallesia integrifolia, Dalbergia nigra and Guarea guidonia. The values of richness and species diversity (H') in five different sample areas ( 0.2 ha) ranged from 33 to 89 and from 2.81 to 3.87, respectively. The forest fragments, although secondary and in a mid-successional stage, had a particular species composition, high diversity and richness, and seem to have floristic influence from both semideciduous and evergreen forests of southeastern Brazil. These characteristics are probably related to the geographic position of the region.
\end{abstract}

Key words: floristic composition, tree diversity, forest fragments, northwestern Rio de Janeiro state.

\section{Introdução}

Embora a definição de "comunidade vegetal" seja ainda controversa na escala espaço-temporal, bem como os melhores métodos para estudá-la (Schilling \& Batista 2008), este termo é amplamente difundido e utilizado no meio científico (Weaver \&
Clements 1938; Carvalho et al. 2006). É de suma importância compreender as peculiaridades que permeiam as comunidades, de modo a acessar as melhores ferramentas para seu conhecimento e preservação, sobretudo no seu aspecto principal, a diversidade de espécies.

\footnotetext{
${ }^{1}$ Universidade Estadual do Norte Fluminense, Programa de Pós-graduação em Ecologia e Recursos Naturais, Av. Alberto Lamego 2000, Parque Califórnia, 28013-620, Campos dos Goytacazes, RJ, Brasil. mauriciodan@ig.com.br

${ }^{2}$ Instituto de Pesquisas Jardim Botânico do Rio de Janeiro, R. Pacheco Leão 915, 22460-030, Rio de Janeiro, RJ, Brasil. jmbraga@jbrj.gov.br

${ }^{3}$ Universidade Estadual do Norte Fluminense, Laboratório de Ciências Ambientais, Av. Alberto Lamego 2000, Parque Califórnia, 28013-620, Campos dos Goytacazes, RJ, Brasil. Autor para correspondência:mtn@uenf.br
} 
De fato o grande número de espécies arbóreas em florestas tropicais há muito chama a atenção (Dobzhansky 1950), e é a principal força motriz para o estudo das comunidades vegetais. Seja para responder perguntas sobre como algumas florestas possuem e mantém tantas espécies (Leigh Jr. et al. 2004), seja para elucidar padrões de distribuição espacial de espécies na comunidade (Nascimento \& Proctor 1997), ou sua distribuição geográfica (Nascimento \& Lima 2008; Scudeller et al. 2001). Além disso, seu estudo é importante para determinação de áreas prioritárias para conservação (MMA 2000; Myers et al. 2000) ou, simplesmente, para caracterização da vegetação (Silva \& Nascimento 2001).

Dentro deste contexto, destaca-se a Mata Atlântica (sensu lato). Este complexo bioma composto de ecossistemas de grande importância ecológica, por abrigar uma parcela significativa da diversidade biológica do Brasil, é um dos biomas mais ameaçados do mundo devido às constantes agressões ou ameaças antrópicas de destruição dos habitats nas suas variadas tipologias e ecossistemas associados (Fundação SOS Mata Atlântica \& INPE 2008; Myers et al. 2000). Originalmente distribuída ao longo da costa atlântica do país, atingindo áreas da Argentina e do Paraguai, a Mata Atlântica abrangia $1.350 .000 \mathrm{~km}^{2}$ no território brasileiro $(15 \%)$ na época pré-colombiana (IBGE 1993). Contudo, atualmente apenas $8 \%$ da área do bioma preservam suas características bióticas originais (MMA 2000). O termo Mata Atlântica na definição sensu lato, engloba as florestas ombrófilas densas e as florestas estacionais semidecíduas do leste, com incursões interiores de cerca de $700 \mathrm{~km}$ (OliveiraFilho \& Fontes 2000), além de ecossistemas associados (Scarano 2002).

Segundo Fidalgo et al. (2009) o estado do Rio de Janeiro possui remanescentes florestais em $c a$. $20 \%$ da sua área original coberta por Mata Atlântica distribuídos em floresta ombrófila densa (FOD) e floresta estacional semidecidual (FES). No caso da FES apenas 10\% de sua área original está vegetada e extremamente fragmentada, com cerca de $50 \%$ dos remanescentes florestais com no máximo 100 ha distribuídos em uma matriz predominantemente agrária. Estes fragmentos, em geral, são ricos em espécies arbóreas das famílias Rutaceae, Fabaceae, Euphorbiaceae, Bignoniaceae e Meliaceae (OliveiraFilho et al. 2005; Nascimento \& Lima 2008). Entretanto, pouco se conhece a florística e estrutura da FES, conforme salientado por Scarano et al. (2009) para o estado do Rio de Janeiro.
É ressaltado a importância deste estudo pelo caráter pioneiro no acesso a composição florística e caracterização estrutural de fragmentos florestais no noroeste do Rio de Janeiro. Partindo-se do princípio que a Bacia Hidrográfica do Rio São Domingos (BHRSD) era coberta por um continuиm florestal e que o estado do Rio de Janeiro é um dos principais centros de diversidade da Mata Atlântica, objetivou-se responder as seguintes questões: qual a composição florística dos fragmentos e que espécies os caracterizam? A comunidade arbórea dos fragmentos da BHRSD encerra altos níveis de riqueza e diversidade florística? Os fragmentos florestais da BHRSD estão em que estádio sucessional?

\section{Material e Métodos}

\section{Área de estudo}

Situada na região noroeste fluminense, a bacia hidrográfica do rio São Domingos (BHRSD) (Fig. 1) tem cerca de $90 \%$ de sua área de $280 \mathrm{~km}^{2}$ ocupada pelo município de São José de Ubá. A BHRSD faz parte do complexo hidrográfico da bacia do rio Paraíba do Sul, onde o rio São Domingos é afluente de segunda ordem. A região estudada está inserida no domínio geoambiental do norte-noroeste Fluminense, que consiste em uma vasta depressão interplanáltica, alternada com alinhamentos serranos de direção estrutural NE-SW. Esta região está contida em um desses alinhamentos serranos, sendo caracterizada pela forte incidência de erosão laminar e em sulcos, sobretudo na área de domínio de argissolos vermelhos e argissolos vermelhoamarelos pouco espessos, em relevo forte ondulado e montanhoso. Estes solos predominam na BHRSD e ocupam cerca de $70 \%$ da área. O clima característico da região é o tropical quente e úmido, com a estação seca (inverno) e chuvosa (verão) bem definidas. As médias térmicas anuais estão em torno de $23^{\circ} \mathrm{C}$, com a média do mês mais quente perto dos $26^{\circ} \mathrm{Ce}$ a média no mês mais frio entre $19^{\circ} \mathrm{C}$ e $20^{\circ} \mathrm{C}$. A pluviometria gira em torno de $1200 \mathrm{~mm}$ anuais. O período seco vai de abril a setembro tendo seu auge nos meses de junho a agosto, caracterizando fortíssima estiagem. O trimestre totaliza aproximadamente $70 \mathrm{~mm}$ de precipitações (RioRuralGef 2007).

De acordo com informações da Fundação SOS Mata Atlântica (2007), o município de São José de Ubá, que originalmente era completamente coberto por Mata Atlântica (sensu lato), hoje possui apenas $4 \%$ de sua cobertura, totalizando 923 ha de floresta 


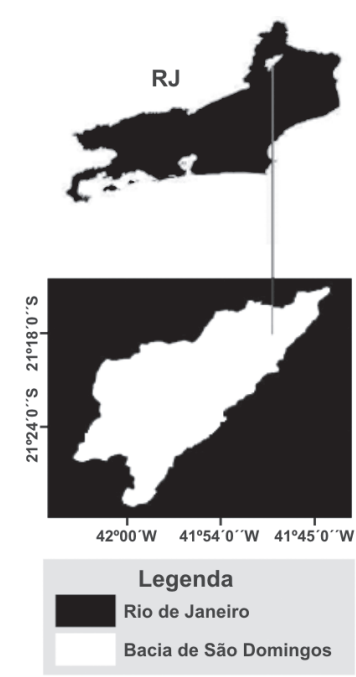

Figura 1 - Localização da bacia hidrográfica do rio São Domingos (BHRSD) dentro dos limites da região noroeste do RJ. (Fonte: Prado \& Di Lullo 2007, adaptado.)

Figure 1 - Location of São Domingos river basin (BHRSD) within the limits of the northwest region of Rio de Janeiro State, Brazil. (Source: Di Lullo \& Prado 2007).

estacional semidecidual submontana, altamente fragmentados, praticamente todos localizados em topo de morros.

Quatro fragmentos florestais foram selecionados para o estudo e estão todos localizados no município de São José de Ubá, RJ. O primeiro fragmento Prosperidade-PRO ( $21^{\circ} 24^{\prime} 42,5^{\prime}$ 'S $\left.42^{\circ} 01^{\prime} 58,8^{\prime \prime} \mathrm{W}\right)$, está localizado na fazenda Prosperidade e representa o maior remanescente florestal da BHRSD (730 ha). Os outros três fragmentos estão localizados em fazendas na microbacia Santa Maria/Cambiocó, sendo eles Camacho ( $21^{\circ} 24^{\prime} 36,3$ 'S $41^{\circ} 55^{\prime} 15,2^{\prime \prime} \mathrm{W}-7,5$ ha), Cambiocó (2123'30,7'S 4155'30,5'W-2,5 ha) e Emboque (21'22'31,9'S 41'55'04,8'W -6,0 ha). Todos estes fragmentos são florestas secundárias e estão localizados em propriedades particulares, apresentando diferentes históricos de perturbações antrópicas, tais como ocorrência de queimada, caça e retirada seletiva de madeira. Com relação aos três fragmentos menores (Camacho - CAM, Cambiocó $\mathrm{CAB}$ e Emboque - EMB), estes vêm sofrendo corte seletivo há várias décadas e registro de queimadas no passado.

\section{Metodologia de campo \\ e amostragem}

Entre outubro de 2007 e outubro de 2008, um total de 25 parcelas de $20 \mathrm{~m} \times 20 \mathrm{~m}$, totalizando uma área amostral de 1 ha, foram alocadas nos quatro fragmentos estudados, sendo 10 na Prosperidade (cinco por subárea) e cinco em cada um dos demais fragmentos selecionados. Para a avaliação fitossociológica-estrutural, todo indivíduo arbustivo-arbóreo vivo enraizado dentro das parcelas e com pelo menos um dos caules (caso houvesse ramificação acima do solo) obedecendo ao critério mínimo de inclusão DAP $\geq 5 \mathrm{~cm}$ foi plaqueteado, amostrado e identificado. No caso de tronco múltiplo foram medidos também os demais ramos para cálculo de área basal do indivíduo. Árvores mortas em pé e lianas (DAP $\geq 5 \mathrm{~cm}$ ) foram apenas contabilizadas. A altura máxima da copa de cada indivíduo foi estimada sempre pelo mesmo observador.

O material testemunho coletado foi herborizado e depositado no herbário UENF, da Universidade Estadual do Norte Fluminense Darcy Ribeiro. A identificação das espécies foi realizada através da comparação dos espécimes coletados com o acervo do herbário UENF e do herbário do Instituto de Pesquisas do Jardim Botânico do Rio de Janeiro (RB), mediante consulta a especialistas e/ou a bibliografia especializada. Foi utilizado o sistema de classificação proposto pela APG II (2003).

\section{Análise dos dados}

De modo a entender melhor as características ecológicas das espécies amostradas, estas foram classificadas dentro das categorias sucessionais ou grupos ecológicos propostos por Gandolfi et al. (1995): pioneiras, secundárias iniciais, secundárias tardias, e sem caracterização (em função da carência de informações, não foram enquadradas em nenhuma das categorias anteriores). Além dessas características, foram também utilizadas as síndromes de dispersão de diásporos de Van der Pijl (1982), sendo as espécies classificadas como: anemocóricas, autocóricas e zoocóricas. Por fim, mediante consultas de bibliografias especializadas com informações acerca da biologia das espécies, bem como baseado em observações de campo e na experiência dos pesquisadores envolvidos, foram atribuídas às espécies categorias relacionadas à posição nos estratos da floresta, potencial ou preferencialmente, ocupado pelas mesmas em fitofisionomias semelhantes à área de estudo. Assim, a estratificação adotada foi a de três estratos: estrato superior (S) ou dossel, médio (M) ou sub-dossel e inferior (I) ou sub-bosque.

A análise fitossociológica-estrutural foi baseada nos parâmetros absolutos e relativos de 
densidade, dominância, frequência, valor de importância (VI), valor de cobertura (VC) e área basal (Mueller-Dombois \& Ellemberg 1974), calculados através do programa FITOPAC (Shepherd 1995).

Para avaliar as diferenças fisionômicas entre as cinco áreas amostrais para os parâmetros densidade, área basal, número relativo de indivíduos perfilhados acima do solo (troncos múltiplos), número relativo de árvores mortas em pé e número de lianas enraizadas dentro das parcelas, foi utilizado o teste de análise de variância (ANOVA). Para efeito de cálculo, os números relativos de indivíduos perfilhados e árvores mortas foram transformados em arco seno da raiz quadrada. No caso de ocorrência de diferenças estatísticas entre as médias do parâmetro analisado foi aplicado o teste a posteriori de Tukey para discriminar as diferenças (Brower \& Zar 1984).

A fim de caracterizar o estádio sucessional dos fragmentos, foram utilizados os parâmetros estruturais descritos pelo CONAMA (1994).

O índice de diversidade de Shannon para espécies (Brower \& Zar 1984) foi calculado, com base no logaritmo natural, para cada um dos fragmentos e para área como um todo. A similaridade de espécies entre os fragmentos foi calculada através do índice de similaridade quantitativo de MorisitaHorn, bem como o índice qualitativo de similaridade de Jaccard (Brower \& Zar 1984). Esses índices também foram calculados através do programa FITOPAC (Shepherd 1995). Os valores de riqueza e diversidade de espécies dos fragmentos estudados foram comparados pelas curvas de rarefação, baseadas no número de indivíduos amostrados de cada uma das espécies nas respectivas áreas. Esta análise foi realizada com o auxílio do software EcoSim 7 (Gotelli \& Entsminger 2001).

\section{Resultados}

\section{Fitossociologia}

A estrutura fisionômica da comunidade variou entre as cinco áreas amostrais consideradas, com os maiores valores de densidade e área basal ocorrendo no fragmento Prosperidade I. Por outro lado, os menores valores para estes dois parâmetros foram registrados em $\mathrm{EMB}$ e $\mathrm{CAB}$, respectivamente (Tab. 1). Em relação à percentagem média de árvores mortas e perfilhadas por parcela não houve diferença estatística entre os fragmentos, com valores variando entre 2,6\% (CAM) a 8,0\% (CAB) para árvores mortas e 5,0\% (PRO2) a 24,0\% (CAB) para árvores perfilhadas. Entretanto, para o número de lianas com $D A P \geq 5 \mathrm{~cm}$ foi observado um maior número para PRO2 e o menor para o $\mathrm{CAB}$ (Tab. 1). Foram amostrados, no total, 1144 indivíduos arbóreos vivos com densidade variando de 905 a 1445 indivíduos/ha por fragmento (Tab. 2). Estes indivíduos foram distribuídos em 198 espécies, pertencentes a 52 famílias botânicas (Anexo 1). Destes, $130(65,5 \%)$ foram identificados em nível específico, 44 (22,2\%) em nível de gênero, 15 em família $(7,5 \%)$ e 7 indeterminados (3,5\%). Além de duas novas espécies, uma do gênero Protium (Burseraceae) e a outra de Pseudopiptadenia (Fabaceae), que estão em processo de descrição por especialistas.

$\mathrm{Na}$ BHRSD as famílias mais ricas em espécies foram Fabaceae (Leguminosae) (36), Euphorbiaceae (14), Meliaceae (12), Nyctaginaceae e Rubiaceae (9), Myrtaceae (8), Lauraceae e Sapotaceae (7), Annonaceae, Moraceae, e Rutaceae (6).

As 10 espécies com os maiores valores de importância (VI) na amostragem geral ocorreram em pelo menos três dos cinco fragmentos estudados (Anexo 1), com exceção de Piptadenia gonoacantha (Mart.) J.F.Marcbr. que esteve presente em apenas dois (CAB e PRO1) e Guarea guidonia (L.) Sleumer que foi amostrada somente no fragmento PRO (PRO1 e PRO2). Entre as espécies mais abundantes na comunidade arbórea da Bacia do Rio São Domingos tiveram destaque Gallesia integrifolia (Spreng.) Harms, Apuleia leiocarpa (Vogel) J.F. Marcbr., Piptadenia gonoacantha, Guarea guidonia, Dalbergia nigra (Vell.) Allemao ex Benth., Parapiptadenia pterosperma (Bojer) Brenan principais componentes do estrato superior na comunidade. No Estrato médio foram destaque Deguelia costata (Benth.) Az. Tozzi, Trichilia sp.1 e Trichilia ellegans A. Juss. Já Sebastiania commersoniana (Baill.) L.B.Sm. \& Downs foi uma espécie típica do sub-bosque. Um total de 69 espécies $(34,7 \%)$ foi representado por um único indivíduo, considerando-se a amostragem total (1,0 ha), representando $6 \%$ do total de indivíduos. Assim essas espécies foram consideradas raras na comunidade (Anexo 1). Entre os fragmentos, o número de espécies raras variou de $2(\mathrm{CAB})$ a 24 (PRO1) (Tab. 2).

Quando analisadas em separado, as cinco áreas amostrais apresentaram uma estrutura fitossociológica diferenciada, que pode ser observada através dos parâmetros fitossociológicos 
Tabela 1 - Principais parâmetros analisados por parcela $(n=5)$ para a estrutura fisionômica da comunidade arbórea amostrada na Bacia do Rio São Domingos, São José de Ubá, RJ. De = densidade média de indivíduos arbóreos vivos, $\mathrm{AB}=$ área Basal média, prf = proporção de indivíduos arbóreos vivos perfilhados, mrt = proporção de indivíduos arbóreos mortos em pé, lna = número médio de lianas lenhosas. Valores médios na mesma coluna seguidos por diferentes letras diferem significativamente $(\leq 0,05)$.

Table 1 - Main parameters measured per plot $(n=5)$ for the physiognomic structure of the tree community studied in the São Domingos river basin, São José de Ubá, RJ, Brazil. De= average density of live trees per plot, $\mathrm{AB}=$ average basal area per plot, prf = proportion of sprouts, $\mathrm{mrt}=$ proportion of standing dead trees, lna = average number of woody lianas. Means in the same column followed by different letters are statistically significantly different $(\leq 0.05)$.

\begin{tabular}{|c|c|c|c|c|c|}
\hline Fragmentos & De (ind. 0,04 ha-1) & $\mathrm{AB}\left(\mathrm{m}^{2} .0,04 \mathrm{ha}^{-1}\right)$ & $\operatorname{prf}(\%)$ & $\operatorname{mrt}(\%)$ & Ina (ind $\left.0.04 \mathrm{ha}^{-1}\right)$ \\
\hline PRO1 & $57,8 \pm 11,71 \mathrm{a}$ & $1,95 \pm 0,43 \mathrm{a}$ & $9,0 \pm 5,2 \mathrm{a}$ & $5,4 \pm 3,8 \mathrm{a}$ & $2,6 \pm 2,07 \mathrm{ab}$ \\
\hline $\mathrm{PRO} 2$ & $52,6 \pm 9,07 \mathrm{ab}$ & $1,13 \pm 0,25 b$ & $4,8 \pm 5,9 \mathrm{a}$ & $4,2 \pm 3,3 \mathrm{a}$ & $3,4 \pm 1,95 \mathrm{a}$ \\
\hline CAM & $38 \pm 12,79 a b$ & $1,04 \pm 0,29 b c$ & $19,6 \pm 6,0 \mathrm{a}$ & $2,3 \pm 1,6 \mathrm{a}$ & $0,8 \pm 0,84 \mathrm{ab}$ \\
\hline EMB & $36,2 \pm 7,89 b$ & $0,73 \pm 0,10 \mathrm{bc}$ & $12,7 \pm 2,1 \mathrm{a}$ & $3,9 \pm 3,3 \mathrm{a}$ & $1,4 \pm 0,89 \mathrm{ab}$ \\
\hline $\mathrm{CAB}$ & $44,2 \pm 15,40 \mathrm{ab}$ & $0,61 \pm 0,16 \mathrm{c}$ & $23,6 \pm 8,0 \mathrm{a}$ & $8,1 \pm 5,9 \mathrm{a}$ & $0,6 \pm 0,55 b$ \\
\hline
\end{tabular}

apresentados nas Tabelas 3 e 4 . Foi observado que entre as 10 espécies de maior VC nas cinco diferentes áreas amostrais, apenas três - Gallesia integrifolia, Apuleia leiocarpa e Pseudobombax endecaphyllum - estiveram presentes em três das áreas, embora ocupando posições fitossociológicas diferentes. Também entre as 10 primeiras e ocorrendo em duas áreas amostrais foram registradas quatro espécies, Dalbergia nigra, Guarea guidonia, Sebastiania commersoniana e Parapiptadenia pterosperma.

\section{Grupos ecológicos}

Com relação às categorias sucessionais, foram observados que entre os fragmentos amostrados o número de espécies tardias, considerando-se as 10 espécies de maior VC, variou de $0(\mathrm{CAB})$ a 7 (EMB) (Tabs. 3 e 4). Quando considerado a amostragem como um todo (Anexo 1), apenas uma espécie foi classificada como secundária tardia entre as 10 mais importantes em VI. Em quatro áreas amostrais houve um equilíbrio entre os grupos das secundárias iniciais (SI) e tardias (ST) (Fig. 2a-b), sendo as espécies pioneiras $(\mathrm{Pi})$ pouco representadas nestes fragmentos. No caso de $\mathrm{CAB}$ houve nítido predomínio de espécies pioneiras e secundárias iniciais e ausência de secundárias tardias. As espécies secundárias iniciais diminuíram em proporção do estrato superior para o inferior, onde neste último, houve predomínio de secundárias tardias na composição. As pioneiras não variaram muito de proporção entre os estratos (Fig. 3a).

Já em relação às síndromes de dispersão, o número de espécies zoocóricas, entre as 10 de maior
VC, variou de duas (CAM e CAB) a cinco (PRO2) nos fragmentos amostrados. Considerando-se a amostragem geral, somente duas espécies com síndrome zoocórica estiveram entre as 10 de maior VI.

A síndrome de dispersão de diásporos zoocórica predominou tanto no número de espécies $(113=56,8 \%)$ quanto de indivíduos $(528=46,2 \%)$, com maior destaque no caso da composição de espécies (Fig. 2c, d). Espécies autocóricas não se destacaram muito no número de espécies $(10=5,0 \%)$ e de indivíduos $(103=9,0 \%)$, porém tiveram um destaque um pouco maior nos fragmentos CAM e EMB onde houve uma maior presença de espécies de Euphorbiaceae e Rutaceae. O fragmento CAB não apresentou espécies autocóricas, mas possuiu domínio de espécies anemocóricas tanto na estrutura quanto na composição.

Houve diminuição na composição de espécies anemocóricas do estrato superior para o inferior e o contrário é válido para as zoocóricas. Porém, observou-se um ligeiro equilíbrio entre espécies anemocóricas e zoocóricas no estrato superior e um domínio de espécies zoocóricas nos estratos médio e inferior (Fig. 3b).

\section{Diversidade e similaridade}

Os valores de riqueza e de diversidade de espécies nas diferentes subáreas amostrais variaram de 33 (CAB) a 89 (PRO1) e 2,81 (CAB) a 3,87 (PRO1), respectivamente. Os fragmentos $\mathrm{PRO} 2$, EMB e CAM tiveram valores similares e intermediários para tais índices, enquanto o fragmento $\mathrm{CAB}$ apresentou valores mais baixos (Tab. 2). A comparação par a par entre as curvas de 
Tabela 2 - Principais parâmetros analisados para espécies e famílias botânicas amostradas nos fragmentos da Bacia do Rio São Domingos, São José de Ubá, RJ, nas cinco diferentes áreas amostrais de 0,2ha cada. FESSM = floresta estacional semidecidual sub-montana, FODTB = floresta ombrófila densa de terras baixas, FODSM = floresta ombrófila densa sub-montana, FESTB = floresta estacional semidecidual de terras baixas, FODM = floresta ombrófila densa montana, FESM = floresta estacional semidecidual montana, perturb. = área com perturbação antrópica, preserv.= área preservada em unidades de conservação. $\mathrm{AB}=$ área basal total em $\mathrm{m}^{2}$ por hectare, $\mathrm{DAP}=$ diâmetro mínimo para inclusão na análise fitossociologica em $\mathrm{cm}, \mathrm{Ni}=$ Número de indivíduos por hectare, $\mathrm{Nsp}=\mathrm{Número}$ de espécies, $\mathrm{sp}$.un. $=$ número de espécies representadas por um único indivíduo na amostragem, H’ = índice de diversidade de Shannon (nats/indiv) para espécies, Nfm = Número de famílias, $\mathrm{J}=$ uniformidade de espécies.

Table 2 - The main parameters analyzed for species and plant families sampled in five areas of 0.2 ha in the São Domingos river basin, São José de Ubá, RJ, Brazil. FESSM = sub-montane semideciduous forest, FODTB $=$ evergreen lowland forest, FODSM $=$ evergreen sub-montane forest, FESTB $=$ semideciduous lowland forest FODM $=$ evergreen montane forest, FESM $=$ semideciduous montane forest, perturb. $=$ disturbed area, preserve. $=$ preserved area. $\mathrm{AB}=$ total basal area in $\mathrm{m}^{2}$ per hectare, $\mathrm{DAP}=$ minimum diameter at breast height $(\mathrm{cm}), \mathrm{Ni}=$ number of individuals per hectare, NSP $=$ number of species, sp.un. = number of species represented by a single individual in the sample, $\mathrm{H}^{\circ}=$ Shannon species diversity index, Nfm $=$ number of families,

$\mathrm{J}=$ uniformity of species.

\begin{tabular}{|c|c|c|c|c|c|c|c|c|c|c|c|}
\hline Município-UF & Fitofisionomia & Área Amostral & $\begin{array}{c}\mathbf{A B} \\
\left.\mathbf{m}^{2} \mathbf{h a}^{-1}\right)\end{array}$ & DAP & Niha $^{-1}$ & Nsp & sp.un. & $\mathbf{H}^{\prime}$ & Nfm & $\mathbf{J}$ & Referência \\
\hline \multicolumn{12}{|c|}{ RJ (região noroeste) } \\
\hline S. José de Ubá-RJ & FESSM/perturb. & PRO1 (0,2 ha) & 48,81 & 5,0 & 1445 & 89 & 24 & 3,87 & 40 & 0,86 & Este estudo \\
\hline S. José de Ubá-RJ & FESSM/perturb. & PRO2 (0,2 ha) & 28,35 & 5,0 & 1315 & 70 & 15 & 3,63 & 35 & 0,85 & Este estudo \\
\hline S. José de Ubá-RJ & FESSM/perturb. & CAM $(0,2$ ha $)$ & 25,89 & 5,0 & 950 & 68 & 13 & 3,84 & 33 & 0,91 & Este estudo \\
\hline S. José de Ubá-RJ & FESSM/perturb. & $\operatorname{EMB}(0,2$ ha $)$ & 18,17 & 5,0 & 905 & 65 & 15 & 3,83 & 28 & 0,92 & Este estudo \\
\hline S. José de Ubá-RJ & FESSM/perturb. & $\mathrm{CAB}(0,2 \mathrm{ha})$ & 15,32 & 5,0 & 1105 & 33 & 2 & 2,81 & 14 & 0,80 & Este estudo \\
\hline S. José de Ubá-RJ & FESSM/perturb. & BHRSD (1,0 ha) & 27,30 & 5,0 & 1144 & 198 & 69 & 4,60 & 52 & 0,87 & Este estudo \\
\hline S. José de Ubá-RJ & FESSM/perturb. & BHRSD (1,0 ha) & 24,91 & 10,0 & 559 & 140 & - & 4,35 & 44 & 0,88 & Este estudo \\
\hline \multicolumn{12}{|c|}{ RJ (região centro norte) } \\
\hline Silva Jardim-RJ & FODTB/perturb. & Faz. Afetiva (0,2 ha) & 24,99 & 5,0 & 1855 & 66 & - & 3,62 & 27 & 0,86 & Carvalho et al. (2009) \\
\hline Silva Jardim-RJ & FODTB/perturb. & Faz. Estreito (0,2 ha) & 25,78 & 5,0 & 1060 & 46 & - & 2,88 & 22 & 0,75 & Carvalho et al. (2009) \\
\hline Silva Jardim-RJ & FODTB/perturb. & Faz. Imbaú (0,2 ha) & 33,44 & 5,0 & 1535 & 59 & - & 3,26 & 24 & 0,80 & Carvalho et al. (2009) \\
\hline Silva Jardim-RJ & FODTB/perturb. & $\begin{array}{l}\text { Faz. Andorinhas } \\
(0,2 \text { ha) }\end{array}$ & 31,66 & 5,0 & 2140 & 76 & - & 3,62 & 29 & 0,84 & Carvalho et al. (2009) \\
\hline Silva Jardim-RJ & FODTB/perturb. & $\begin{array}{l}\text { Sítio do Professor } \\
(0,2 \text { ha })\end{array}$ & 48,96 & 5,0 & 1400 & 58 & - & 3,26 & 27 & 0,81 & Carvalho et al. (2009) \\
\hline Silva Jardim-RJ & FODTB/perturb. & $\begin{array}{l}\text { Região do Imbaú } \\
(1,0 \text { ha })\end{array}$ & - & 5,0 & 1598 & 161 & - & 4,00 & 34 & - & Carvalho et al. (2009) \\
\hline
\end{tabular}




\begin{tabular}{|c|c|c|c|c|c|c|c|c|c|c|c|}
\hline Município-UF & Fitofisionomia & $\begin{array}{l}\text { Área Amostral } \\
\left(\mathbf{m}^{2} \mathbf{h a}^{-1}\right)\end{array}$ & $\mathbf{A B}$ & DAP & Niha $^{-1}$ & Nsp & sp.un. & $\mathbf{H}^{\prime}$ & Nfm & $\mathbf{J}$ & Referência \\
\hline Rio das Ostras-RJ & FODTB/preserv. & $\begin{array}{l}\text { REBIO União } \\
(1,2 \text { ha) }\end{array}$ & 32 & 10,0 & - & 250 & - & 4,90 & - & 0,87 & $\begin{array}{l}\text { P.J.F.P. Rodrigues } \\
\text { (dados não publicados) }\end{array}$ \\
\hline Silva Jardim-RJ & FODSM/perturb. & $\begin{array}{l}\text { Faz. Biovert } \\
(0,36 \text { ha })\end{array}$ & 21,2 & 3,2 & 1823 & 98 & _- & 3,46 & 40 & 0,75 & Borém \& Ramos (2001) \\
\hline Silva Jardim-RJ & FODSM/perturb. & $\begin{array}{l}\text { Faz. Biovert } \\
(0,36 \text { ha })\end{array}$ & 18,4 & 3,2 & 1450 & 129 & - & 4,14 & 43 & 0,85 & $\begin{array}{l}\text { Borém \& Oliveira- } \\
\text { Filho (2002) }\end{array}$ \\
\hline Rio Bonito-RJ & FODTB/perturb. & $\begin{array}{l}\text { Faz. Rio Vermelho } \\
(0,4 \text { ha })\end{array}$ & 11,6 & 5,0 & 1745 & 106 & _ & 3,91 & 32 & 0,84 & Carvalho et al. (2007) \\
\hline \multicolumn{12}{|c|}{ RJ (região norte) } \\
\hline Campos-RJ & FODSM/preserv. & Imbé - 50m (0,6 ha) & 41,9 & 10,0 & 780 & 125 & _ & 4,21 & 31 & _ & Moreno et al. (2003) \\
\hline Campos-RJ & FODSM/preserv. & Imbé - 250m (0,6 ha) & 34,8 & 10,0 & 815 & 145 & _- & 4,30 & 39 & _ & Moreno et al. (2003) \\
\hline S. F. Itabapoana-RJ & FESTB/perturb. & Carvão (1,0 ha) & 15 & 10,0 & 564 & 83 & _- & 3,21 & 34 & 0,77 & $\begin{array}{l}\text { Silva \& Nascimento } \\
(2001)\end{array}$ \\
\hline Campos-RJ & FESTB/perturb. & $\begin{array}{l}\text { Bom Jesus } \\
\text { ( } 84 \text { pontos })\end{array}$ & 17,3 & 3,2 & 840 & 105 & _ & 4,02 & 35 & 0,89 & Carvalho et al. (2006a) \\
\hline \multicolumn{12}{|c|}{ ES (regiões sul e centro norte) } \\
\hline Cachoeiro-ES & FESSM/perturb. & $\begin{array}{l}\text { FLONA Pacotuba } \\
(2,4 \text { ha })\end{array}$ & - & 5,0 & 1487 & 258 & _ & 3,31 & 53 & 0,60 & $\begin{array}{l}\text { K.M.P.A. Archanjo } \\
\text { (dados não publicados) }\end{array}$ \\
\hline Cachoeiro-ES & FESSM/preserv. & $\begin{array}{l}\text { RPPN Cafundó } \\
(2,5 \text { ha) }\end{array}$ & - & 5,0 & 1823 & 258 & - & 4,13 & 52 & 0,74 & $\begin{array}{l}\text { K.M.P.A. Archanjo } \\
\text { (dados não publicados) }\end{array}$ \\
\hline Santa Tereza-ES & FODM/preserv. & $\begin{array}{l}\text { EB Santa Lúcia } \\
(1,02 \text { ha })\end{array}$ & 47,94 & 6,4 & 2190 & 385 & - & 5,50 & 64 & - & $\begin{array}{l}\text { Thomaz \& Monteiro } \\
\text { (1997) }\end{array}$ \\
\hline \multicolumn{12}{|c|}{ MG (regiões sul e sudeste (Zona da Mata)) } \\
\hline Tiradentes-MG & FESM/perturb. & $\begin{array}{l}\text { Serra de S. José } \\
(0,9 \text { ha })\end{array}$ & 19,79 & 5,0 & 2387 & 130 & - & 4,24 & 48 & 0,87 & Gonzaga et al. (2008) \\
\hline Ibituruna-MG & FESM/perturb. & $\begin{array}{l}\text { Faz. Coqueiro } \\
(1,04 \text { ha) }\end{array}$ & - & 5,0 & 970 & 171 & - & 4,20 & 54 & 0,90 & Silva et al. (2003) \\
\hline Marliéria-MG & FESSM/perturb. & $\begin{array}{l}\text { PE Rio Doce } \\
\text { (200 pontos) }\end{array}$ & 26,94 & 4,8 & 800 & 143 & - & 3,98 & 38 & 0,80 & Lopes et al. (2002) \\
\hline Lavras-MG & FESM/perturb. & $\begin{array}{l}\text { PE Rio Bonito } \\
(2,4 \text { ha })\end{array}$ & 20,5 & 5,0 & 1724 & 213 & - & 4,56 & 58 & 0,85 & Dalanesi et al. (2004) \\
\hline
\end{tabular}


Tabela 3 - Parâmetros fitossociológicos analisados para a comunidade arbórea amostrada no fragmento "Prosperidade" na Bacia do Rio São Domingos, São José de Ubá, RJ, nas áreas amostrais I e II. Ni = número de indivíduos, DR = densidade relativa, $\mathrm{DoR}=$ dominância relativa, $\mathrm{VC}=$ valor de cobertura, $\mathrm{AB}=$ área basal. Siglas dos Grupos Ecológicos: $\mathrm{CS}=$ categoria sucessional, $\mathrm{ST}$ = secundária tardia, $\mathrm{SI}=$ secundária inicial, $\mathrm{PI}=$ pioneira, $\mathrm{SD}=$ síndrome de dispersão, ane $=$ anemocoria, $z 00=$ zoocoria, aut = autocoria, $\mathrm{NC}=$ não classificada por carência de informações pertinentes.

Table 3 - Phytosociological parameters for the tree community sampled in two 0.2-ha areas (I and II) in the Prosperidade fragment in the São Domingos river basin, São José de Ubá, RJ, Brazil. Ni = number of individuals, DR= relative density, DoR= relative dominance, $\mathrm{VC}=$ cover value, $\mathrm{AB}=$ basal area $\mathrm{CS}=$ successional category, $\mathrm{ST}=$ late secondary, $\mathrm{SI}=$ early secondary, $\mathrm{PI}=$ pioneer, ane $=$ anemochory, zoo $=$ zoochory, aut $=$ autochory, $\mathrm{NC}=$ not classified due to lack of information.

\begin{tabular}{|c|c|c|c|c|c|c|c|}
\hline Espécie & CS & SD & $\mathbf{N i}$ & DR & DoR & $\mathrm{VC}$ & $\mathbf{A B}$ \\
\hline \multicolumn{8}{|c|}{ Prosperidade I (0,2 ha) } \\
\hline Apuleia leiocarpa & SI & ane & 15 & 5,19 & 16,47 & 21,66 & 1,61 \\
\hline Gallesia integrifolia & $\mathrm{ST}$ & ane & 30 & 10,38 & 7,88 & 18,26 & 0,77 \\
\hline Dalbergia nigra & SI & ane & 25 & 8,65 & 6,49 & 15,14 & 0,63 \\
\hline Guarea guidonia & SI & zoo & 24 & 8,3 & 4,72 & 13,02 & 0,46 \\
\hline Anadenanthera colubrina & SI & ane & 2 & 1,04 & 9,61 & 10,64 & 0,94 \\
\hline Vochysia sp.1 & SI & ane & 7 & 2,42 & 4,39 & 6,81 & 0,43 \\
\hline Siparuna guianensis & ST & zoo & 13 & 4,5 & 1,83 & 6,33 & 0,18 \\
\hline Lonchocarpus cultratus & SI & ane & 7 & 2,42 & 2,48 & 4,91 & 0,24 \\
\hline Simarouba amara & SI & zoo & 1 & 0,35 & 4,06 & 4,4 & 0,40 \\
\hline Erythroxyllum pulchrum & ST & zoo & 6 & 2,08 & 2,13 & 4,2 & 0,21 \\
\hline Total Parcial (10 spp.) & - & - & 130 & 45,33 & 60,06 & 105,37 & 5,86 \\
\hline Total Outras (78 spp.) & - & - & 159 & 54,67 & 40 & 94,67 & 3,87 \\
\hline Total Geral (0,2 ha) & - & - & 289 & 100 & 100,06 & 200,04 & 9,74 \\
\hline \multicolumn{8}{|c|}{ Prosperidade II (0,2ha) } \\
\hline Gallesia integrifolia & ST & ane & 27 & 10,27 & 28,89 & 39,16 & 1,64 \\
\hline Guarea guidonia & SI & zoo & 13 & 4,94 & 8,04 & 12,99 & 0,46 \\
\hline Trichilia sp. 1 & SI & zoo & 25 & 9,51 & 3,17 & 12,68 & 0,18 \\
\hline Sebastiania commersoniana & ST & aut & 23 & 8,75 & 1,96 & 10,71 & 0,11 \\
\hline Guarea macrophylla & ST & zoo & 11 & 4,18 & 4,25 & 8,44 & 0,24 \\
\hline Trichilia ellegans & ST & zoo & 14 & 5,32 & 2,96 & 8,28 & 0,17 \\
\hline Jacaranda brasiliana & SI & ane & 9 & 3,42 & 4,85 & 8,28 & 0,28 \\
\hline Swartzia myrtifolia & ST & zoo & 14 & 5,32 & 2,23 & 7,55 & 0,13 \\
\hline Pseudobombax endecaphyllum & SI & ane & 6 & 2,28 & 4,18 & 6,46 & 0,24 \\
\hline Apuleia leiocarpa & SI & ane & 5 & 1,90 & 2,89 & 4,79 & 0,16 \\
\hline Total Parcial (10 spp.) & - & - & 147 & 55,89 & 63,42 & 119,34 & 3,60 \\
\hline Total Outras (60 spp.) & - & - & 116 & 44,10 & 36,58 & 80,68 & 2,07 \\
\hline Total Geral (0,2 ha) & _- & _- & 263 & 99,99 & 100,00 & 200,02 & 5,67 \\
\hline
\end{tabular}


Tabela 4 - Parâmetros fitossociológicos analisados para a comunidade arbórea amostrada nos fragmentos Camacho, Emboque e Cambiocó, na Bacia do Rio São Domingos, São José de Ubá, RJ, nas suas respectivas áreas amostrais de 0,2 ha cada. $\mathrm{Ni}=$ número de indivíduos, $\mathrm{DR}=$ densidade relativa, $\mathrm{DoR}=$ dominância relativa, $\mathrm{VC}=$ valor de cobertura, $\mathrm{AB}=$ área basal. Siglas dos Grupos Ecológicos: $\mathrm{CS}=$ categoria sucessional, $\mathrm{ST}=$ secundária tardia, $\mathrm{SI}=$ secundária inicial, $\mathrm{Pi}=$ pioneira, $\mathrm{SD}=$ síndrome de dispersão, ane $=$ anemocoria, $z 00=$ zoocoria, aut $=$ autocoria, $\mathrm{NC}=$ não classificada por carência de informações.

Table 4 - Phytosociological parameters for the tree community sampled in 0.2-ha in the forest fragments Camacho, Emboque and Cambiocó in the São Domingos river basin, São José de Ubá, RJ, Brazil. Ni = number of individuals, DR= relative density, DoR= relative dominance, $\mathrm{VC}=$ cover value, $\mathrm{AB}=$ basal area. $\mathrm{CS}=$ successional category, $\mathrm{ST}=$ late secondary, $\mathrm{SI}=$ early secondary, $\mathrm{PI}=$ pioneer, ane $=$ anemochory, $\mathrm{zoo}=$ zoochory, aut $=$ autochory, $\mathrm{NC}=$ not classified due to lack of information.

\begin{tabular}{|c|c|c|c|c|c|c|c|}
\hline Espécie & CS & SD & $\mathrm{Ni}$ & DR & DoR & $\mathrm{VC}$ & $\mathbf{A B}$ \\
\hline \multicolumn{8}{|c|}{ Camacho (0,2ha) } \\
\hline Ramisia brasiliensis & SI & ane & 16 & 8,42 & 16,14 & 24,56 & 0,84 \\
\hline Joannesia princeps & $\mathrm{Pi}$ & aut & 14 & 7,37 & 10,07 & 17,44 & 0,52 \\
\hline Pterigota brasiliensis & ST & ane & 4 & 2,11 & 12,19 & 14,30 & 0,63 \\
\hline Matayba sp. & SI & zoo & 11 & 5,79 & 7,93 & 13,72 & 0,41 \\
\hline Gallesia integrifolia & $\mathrm{ST}$ & ane & 5 & 2,63 & 7,66 & 10,29 & 0,40 \\
\hline Parapiptadenia pterosperma & SI & ane & 11 & 5,79 & 3,57 & 9,35 & 0,18 \\
\hline Sebastiania commersoniana & ST & aut & 9 & 4,74 & 0,48 & 5,22 & 0,02 \\
\hline Pseudobombax endecaphyllum & SI & ane & 2 & 1,05 & 3,70 & 4,75 & 0,19 \\
\hline Ficus eximia & SI & zoo & 1 & 0,53 & 4,09 & 4,61 & 0,21 \\
\hline Indeterminada 7 & $\mathrm{NC}$ & $\mathrm{NC}$ & 3 & 1,58 & 2,69 & 4,27 & 0,14 \\
\hline Total Parcial (10 spp.) & - & - & 76 & 40,01 & 68,52 & 108,51 & 3,55 \\
\hline Total Outras (58 spp.) & - & _- & 114 & 59,99 & 31,48 & 91,49 & 1,77 \\
\hline Total Geral (0,2 ha) & - & - & 190 & 100 & 100,00 & 200,00 & 5,18 \\
\hline \multicolumn{8}{|c|}{ Emboque (0,2ha) } \\
\hline Pseudobombax endecaphyllum & SI & ane & 3 & 1,66 & 12,38 & 14,04 & 0,45 \\
\hline Neoraputia alba & ST & aut & 16 & 8,84 & 4,03 & 12,87 & 0,15 \\
\hline Metrodorea nigra & $\mathrm{ST}$ & aut & 12 & 6,63 & 5,85 & 12,48 & 0,21 \\
\hline Trigoniodendron espiritusanctense & ST & zoo & 8 & 4,42 & 6,12 & 10,54 & 0,22 \\
\hline Astronium concinum & ST & ane & 3 & 1,66 & 7,42 & 9,08 & 0,27 \\
\hline Chrysophyllum gonocarpum & $\mathrm{ST}$ & zoo & 9 & 4,97 & 2,87 & 7,84 & 0,10 \\
\hline Pseudopiptadenia contorta & SI & ane & 4 & 2,21 & 5,22 & 7,43 & 0,19 \\
\hline Trichilia pseudostipulares & ST & zoo & 10 & 5,52 & 1,81 & 7,33 & 0,07 \\
\hline Pachira sp.1 & SI & ane & 4 & 2,21 & 5,06 & 7,27 & 0,18 \\
\hline Copaifera lucens & $\mathrm{ST}$ & zoo & 4 & 2,21 & 4,95 & 7,16 & 0,18 \\
\hline Total Parcial (10 spp.) & - & - & 73 & 40,33 & 55,71 & 96,04 & 2,02 \\
\hline Total Outras (55 spp.) & - & - & 108 & 59,67 & 44,78 & 104,45 & 2,06 \\
\hline Total Geral (0,2 ha) & - & - & 181 & 100 & 100,49 & 200,49 & 3,63 \\
\hline \multicolumn{8}{|c|}{ Cambiocó (0,2ha) } \\
\hline Piptadenia gonoacantha & $\mathrm{Pi}$ & ane & 43 & 19,46 & 17,40 & 36,85 & 0,53 \\
\hline Peltophorum dubium & SI & ane & 22 & 9,95 & 13,18 & 23,13 & 0,40 \\
\hline Deguelia costata & SI & ane & 33 & 14,93 & 7,94 & 22,87 & 0,24 \\
\hline
\end{tabular}




\begin{tabular}{lllllllc}
\hline Espécie & CS & SD & Ni & DR & DoR & VC & AB \\
\hline Albizia polycephala & SI & ane & 5 & 2,26 & 20,57 & 22,83 & 0,63 \\
Parapiptadenia pterosperma & SI & ane & 19 & 8,60 & 10,41 & 19,01 & 0,32 \\
Neea sp.1 & SI & zoo & 14 & 6,33 & 4,61 & 10,94 & 0,14 \\
Machaerium aff. acutifolium & SI & ane & 12 & 5,43 & 3,56 & 8,99 & 0,11 \\
Dalbergia nigra & SI & ane & 11 & 4,98 & 2,56 & 7,54 & 0,08 \\
Brosimum guianense & SI & zoo & 11 & 4,98 & 1,46 & 6,43 & 0,04 \\
Apuleia leiocarpa & SI & ane & 5 & 2,26 & 3,39 & 5,65 & 0,10 \\
Total Parcial (10 spp.) & - & - & 175 & 79,18 & 85,08 & 164,24 & 2,61 \\
Total Outras (23 spp.) & - & - & 46 & 33,00 & 15,30 & 48,30 & 0,46 \\
Total Geral (0,2 ha) & - & - & $\mathbf{2 2 1}$ & $\mathbf{1 1 2 , 1 8}$ & $\mathbf{1 0 0 , 3 8}$ & $\mathbf{2 1 2 , 5 4}$ & $\mathbf{3 , 0 6}$ \\
\hline
\end{tabular}

rarefação para riqueza (Fig. 4a) e para diversidade de espécies (Fig. 4b) realizada a partir da curva de menor número de indivíduos (EMB, 181 ind.) e observando a existência ou não de sobreposição de intervalos de confiança, indicou a ocorrência de diferença significativa entre o fragmento $\mathrm{CAB}$ e os demais, tanto para a riqueza quanto para a diversidade de espécies. Uma menor riqueza de espécies também foi observada entre o fragmento $\mathrm{PRO} 2$ e os fragmentos PRO1, CAM e EMB. Entretanto, não houve diferença significativa em diversidade de espécies entre PRO2 e os fragmentos PRO1, CAM e EMB. Vale ressaltar que CAM e EMB, com área inferior a 10 ha, apresentaram níveis de diversidade equivalentes ao do maior fragmento (PRO, $730 \mathrm{ha}$ ).

Em relação à similaridade de espécies foi observada uma baixa similaridade entre os fragmentos, com valores do índice de Jaccard variando entre 0,12 e 0,32 , sendo o maior valor entre os fragmentos PRO1 e PRO2 (Fig. 5) Este padrão de similaridade foi mantido quando utilizado para o cálculo o índice quantitativo de Morisita-Horn, revelando a ocorrência de uma alta substituição de espécies entre os fragmentos amostrados (diversidade $\beta$ ).

\section{Discussão}

Os valores de densidade arbórea encontrados nos fragmentos estudados (905 a 1445 ind.ha $^{-1}$ ), quando comparados com os resultados de outras FES apresentados na Tabela 2, estão no limite mínimo ou médio observado para este tipo florestal (Tab. 2). Com relação à área basal por hectare, verificou-se que a maioria dos fragmentos estudados estão com valores inferiores a $30 \mathrm{~m}^{2} \cdot \mathrm{ha}^{-1}$, e assim, dentro dos valores normalmente observados para fragmentos perturbados de FES. Como exceção, ocorreu o fragmento PRO1 que apresentou valor de $48,8 \mathrm{~m}^{2}$.ha-1. Valores superiores a $30 \mathrm{~m}^{2}$.ha ${ }^{-1}$ são atribuídos às florestas maduras ou bem preservadas (CONAMA 1994).

Os valores de porcentagem de árvores mortas na comunidade da BHRSD (2,6 a 8,3\%), quando comparados com outras áreas de mata no estado do Rio de Janeiro mais preservadas como a Mata do Imbé (1,5\%) (Moreno et al. 2003) e a Reserva Biológica União (5,5\%) (P.J.F.P. Rodrigues, dados não publicados), ou com áreas sujeitas a um maior grau de perturbação antrópica como a Mata do Rio Vermelho (10,1\%) (Carvalho et al. 2007) e a Mata do Carvão (11\%) (Silva \& Nascimento 2001) indicam que a maioria dos fragmentos estudados apresenta valores dentro ou próximos ao limite superior encontrado para áreas preservadas, com exceção do fragmento $\mathrm{CAB}(8,3 \%)$. Entretanto, em relação aos indivíduos arbóreos com troncos múltiplos, os valores observados de 5,3\% a 24\% na BHRSD foram muito superiores ao encontrado para área de floresta preservada, $1,7 \%$ na Reserva Biológica União (e.g. P.J.F.P. Rodrigues, dados não publicados) e em geral também superiores aos encontrados para áreas de matas perturbadas no estado do Rio de janeiro, 1,6\% (Silva \& Nascimento 2001) e 8,3\% (Carvalho et al. 2007). Em CAB a porcentagem elevada de indivíduos com troncos múltiplos (24\%) parece estar relacionada ao alto grau de perturbação (corte raso) sofrido por este fragmento. Além disso, a maioria das árvores com troncos ramificados era de Piptadenia gonoacantha, uma espécie pioneira e indicadora de perturbação (Araújo et al. 2006). 

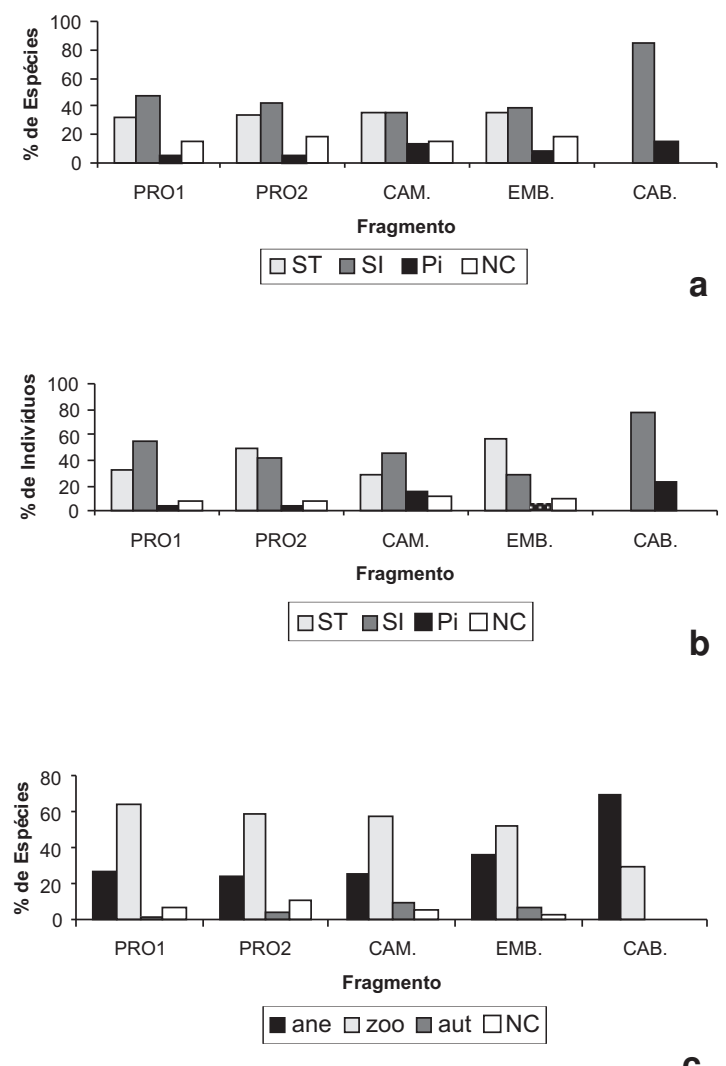

C

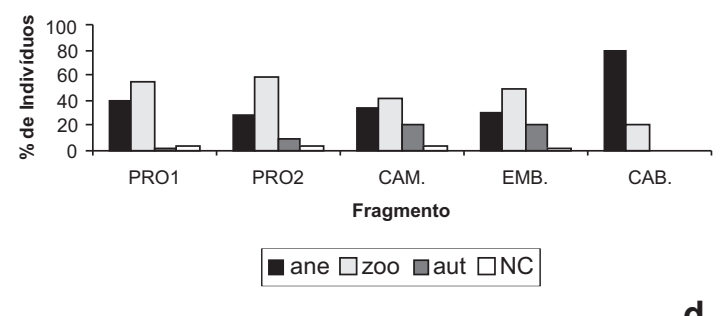

Figura 2 - Grupos ecológicos, representados em porcentagem, das espécies e indivíduos amostrados nos fragmentos PRO1, PRO2, CAM., EMB. e CAB., na BHRSD, São José de Ubá, RJ. a. Espécies por categoria sucessional; b) indivíduos por categoria sucessional; c) espécies por síndromes de dispersão; d) indivíduos por síndrome de dispersão. $\mathrm{ST}=$ secundária tardia, $\mathrm{SI}=$ secundária inicial, $\mathrm{Pi}=$ pioneira; ane $=$ anemocoria, $\mathrm{zoo}=$ zoocoria, aut= autocoria; $\mathrm{NC}=$ não classificado.

Figure 2 - Ecological groups, represented in percentage of species and individuals sampled in fragments PRO1, PRO2, CAM, EMB and CAB, in BHRSD, São José de Ubá, RJ, Brazil. a) species by successional categories; b) individuals by category succession; c. species per dispersal syndrome; d. individuals by dispersal syndrome. ST = late secondary, early secondary $\mathrm{SI}=, \mathrm{Pi}=$ pioneer; ane $=$ anemochory, $\mathrm{zoo}=$ zoochory aut $=$ autocory; $\mathrm{NC}=$ not classified.
Embora a alta densidade de lianas esteja, em geral, relacionada a áreas perturbadas (Putz \& Mooney 1991) é ressaltado que houve uma maior porcentagem de lianas encontradas nos fragmentos aos quais foram atribuídos características de ambiente mais conservado (PRO1 e PRO2). Este fato parece estar relacionado ao critério mínimo de inclusão (DAP $\geq 5 \mathrm{~cm}$ ), que subestimou a densidade de lianas nas áreas menos conservadas, visto que áreas recentemente impactadas são ricas em lianas ou trepadeiras finas (caules de baixo calibre), quando comparadas a locais que sofreram perturbações há mais tempo (Putz \& Mooney 1991).

Diante do exposto, percebe-se que os fragmentos estudados apresentaram características estruturais indicadoras de perturbações antrópicas ocorridas em épocas passadas e/ou recentes, caracterizando-os como formações florestais secundárias. Baseando-se na classificação das florestas secundárias (CONAMA 1994), os fragmentos $\mathrm{CAB}$, CAM e EMB podem ser classificados na classe estágio médio de regeneração. Entretanto, o fragmento $\mathrm{CAB}$ apresentou algumas características que também o aproximam do estágio inicial de sucessão secundária, como a presença de espécies predominantemente heliófitas (pioneiras e secundárias iniciais) e ausência de espécies esciófitas (secundárias tardias). Já o fragmento PRO apresentou nas duas áreas amostrais PRO1 e PRO2 características que se encaixam na definição de Estágio Avançado de regeneração, com a área basal média superior a $28 \mathrm{~m}^{2} \cdot \mathrm{ha}^{-1}$.

Apesar das diferenças fisionômicas apresentadas pelos fragmentos florestais, os níveis de diversidade e riqueza de espécies encontradas foram muito próximos entre si, com exceção do fragmento $\mathrm{CAB}$ que se mostrou o mais pobre em espécies com valores próximos aos encontrados para áreas severamente alteradas de Mata Atlântica (Carvalho et al. 2009).

Salienta-se que fragmentos considerados pequenos, como CAM e EMB (menores que $10 \mathrm{ha}$ ), tiveram níveis de diversidade e riqueza de espécies equivalentes ao do maior fragmento (PRO, $730 \mathrm{ha}$ ) e a ocorrência de espécies ameaçadas (e.g. Couratari asterotricha Prance) e/ou novas (e.g. Pseudopiptadenia sp. nov), indicando sua importância para conservação. Fato semelhante foi observado por Carvalho et al. (2009) para pequenos fragmentos de FODSM na Bacia do Rio São João.

Em geral, fragmentos de FES são menos ricos e diversos em espécies arbóreas que os de FOD 


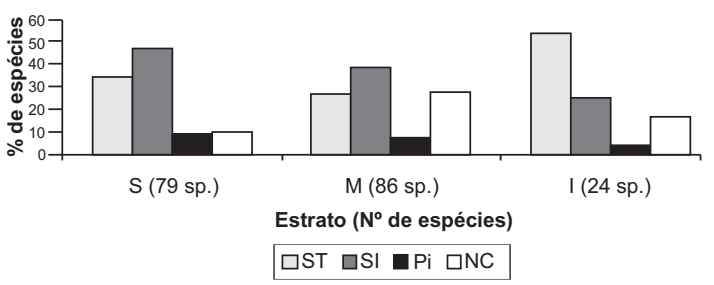

a

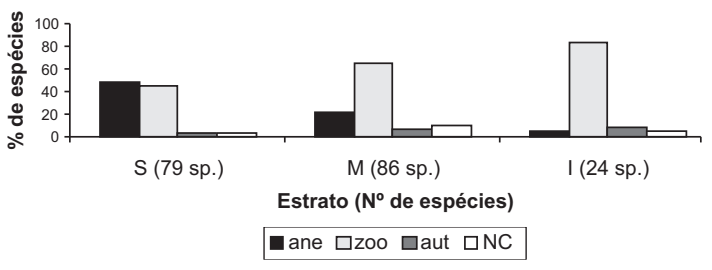

b

Figura 3 - Grupos ecológicos, representados em porcentagem, das espécies amostradas nos fragmentos PRO1, PRO2, CAM., EMB. e CAB., na BHRSD, São José de Ubá, RJ. A) Categoria sucessional das espécies por estrato florestal preferencial de ocupação. B) Síndrome de dispersão das espécies por estrato preferencial de ocupação. $\mathrm{ST}=$ secundária tardia, $\mathrm{SI}=$ secundária inicial, $\mathrm{Pi}=$ pioneira; ane $=$ anemocoria, $\mathrm{zoo}=$ zoocoria, aut= autocoria; $\mathrm{NC}=$ não classificado.

Figure 3 - Ecological groups (\%) in fragments PRO1, PRO2, CAM, BME and CAB in BHRSD, St. Jose de Uba, RJ, Brazil. a. classification by preferred stratum and successional status; $b$. dispersal mode of species by preferred stratum. ST = late secondary, $\mathrm{SI}=$ early secondary, $\mathrm{Pi}=$ pioneer; ane = anemochory, $\mathrm{zoo}=$ zoochory aut $=$ autocory, $\mathrm{NC}=$ not classified.

(Oliveira-Filho \& Fontes 2000). As florestas da BHRSD, apesar de perturbadas, apresentaram uma diversidade e riqueza de espécies superior à observada em outras áreas de FES e mesmo para alguns fragmentos florestais de FODSM (Tab. 2) Assim, esta diversidade aliada à baixa similaridade de espécies encontrada entre os fragmentos da BHRSD parece estar relacionada à heterogeneidade de habitat, conforme observado na Bacia do Rio São João (e.g. Carvalho et al. 2008). Um caso de dissimilaridade florística também foi relatado por Carvalho et al. (2009) em fragmentos perturbados de FODSM, utilizando metodologia de amostragem semelhante ao presente estudo (cinco amostras de 0,2 ha cada).

Entre as 20 famílias botânicas citadas por Oliveira-Filho \& Fontes (2000) como as mais ricas em espécies em FES do Bioma Mata Atlântica, 11
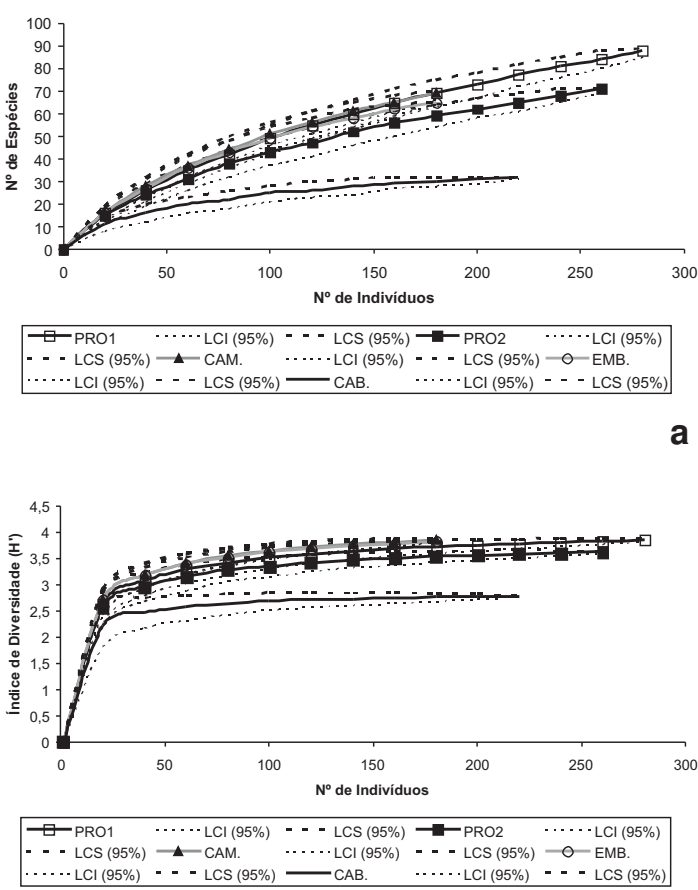

Figura 4 - Curvas de rarefação de Riqueza de espécies e índice de diversidade de Shannon (H') por número de indivíduos amostrados nos fragmentos PRO1, PRO2, CAM., EMB. e CAB., na BHRSD, São José de Ubá, RJ. a. riqueza; b. diversidade. Limite de confiança superior (LCS) e limite de confiança inferior (LCI).

Figure 4 - Rarefaction curves of species richness and values of Shannon diversity index $\left(\mathrm{H}^{\prime}\right)$ in the fragments PRO1, PRO2, CAM, BME and CAB in BHRSD, San Jose de Uba, RJ, Brazil. a. species richness; b. diversity. LCS, upper confidence limit; LCI, lower confidence limit.

delas também estiveram entre as mais ricas na BHRSD, Fabaceae (Leguminosae) (36), Euphorbiaceae (14), Meliaceae (12), Nyctaginaceae e Rubiaceae (9), Myrtaceae (8), Lauraceae e Sapotaceae (7), Annonaceae, Moraceae, e Rutaceae (6), duas delas não foram registradas com nenhuma espécie, Solanaceae e Monimiaceae e sete famílias estiveram presentes, porém com menor riqueza, Bignoniaceae (5), Sapindaceae (4), Apocynaceae (2) e Melastomataceae, Asteraceae, Clusiaceae e Myrsinaceae (1). Entre aquelas famílias que também mereceram destaque pela riqueza em espécies na BHRSD, com cinco espécies cada, mas que foram citadas pelos referidos autores entre as mais ricas em outras formações florestais brasileiras estiveram Salicaceae, citada para florestas ombrófilas da Mata Atlântica e da Amazônia e Malvaceae, citada para florestas ombrófilas da Amazonia. 


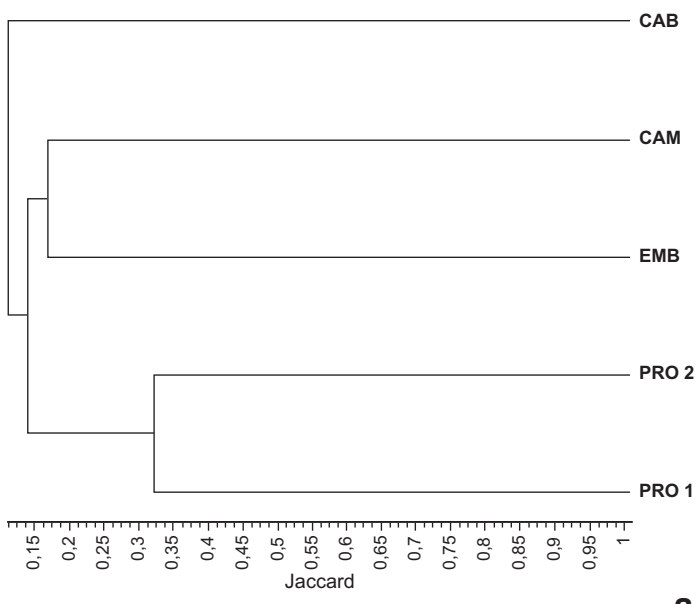

a

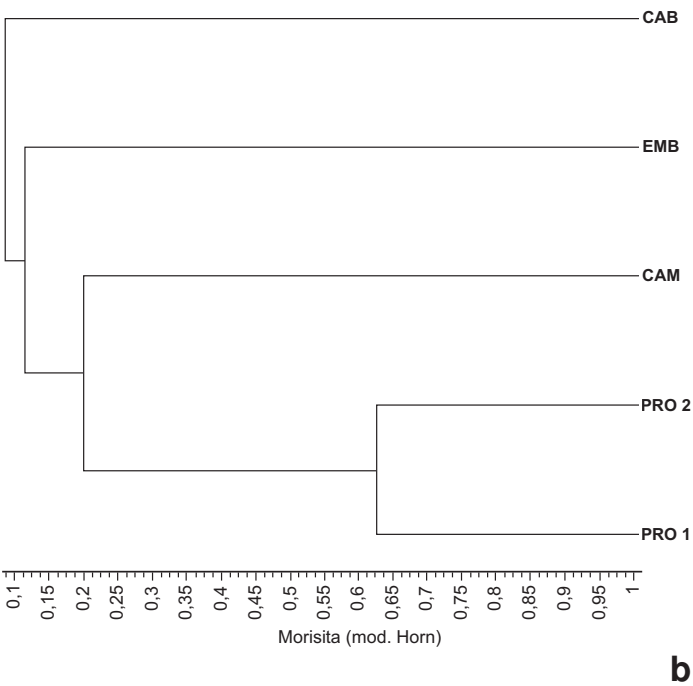

Figura 5 - Dendrogramas de similaridade de espécies entre as áreas amostrais PRO1, PRO2, CAM., EMB. e CAB., nos fragmentos na BHRSD, São José de Ubá, RJ, através do método de agrupamento pela média de grupo (UPGMA). a. Índice de similaridade de Jaccard; b. Índice de similaridade de Morisita-Horn.

Figure 5-Dendrogram of species similarity among the sample areas PRO1, PRO2, CAM, EMB and CAB in forest fragments in the BHRSD, São José de Ubá, RJ, Brazil, by using clustering by group mean (UPGMA). a. Jaccard similarity index; b. Morisita-Horn index.

Com relação à composição de espécies, foi notável a presença de espécies de extrema importância conservacionista entre aquelas identificadas na BHRSD. Dentre estas, sete fazem parte da Lista Oficial de Espécies da Flora Brasileira
Ameaçada de Extinção, de setembro de 2008, do Ministério do Meio Ambiente: Dalbergia nigra (Vell.) Allemao ex Benth. esteve entre as espécies mais abundantes na comunidade (41 indivíduos), alcançando a quarta posição em valor de importância na BHRSD.; Brosimum glaziovii Taub. com nove indivíduos, esteve ausente apenas nos fragmentos EMB e CAB; Trigoniodendron spiritusanctense E.F. Guim. \& J.R. Miguel. destacou-se entre as dez espécies com maior VC apenas no fragmento EMB com oito indivíduos; Euterpe edulis Mart., Melanopsidium nigrum Colla, Chrysophyllum imperiale (Linden ex K. Koch \& Fintelm.) Benth. \& Hook. f. e Couratari asterotricha foram representadas por no máximo quatro indivíduos na amostragem total, porém não foi possível afirmar se estas ocorrem naturalmente em baixas densidades na comunidade ou se tiveram suas populações reduzidas por impactos antrópicos.

A espécie que ocupou a primeira colocação em VI na comunidade da BHRSD foi Gallesia integrifolia. Esta espécie não aparece, em geral, com destaque nos levantamentos fitossociológicos no estado do Rio de Janeiro, exceto em Cachoeiras de Macacú (Kurtz \& Araujo 2000) e em Campos dos Goytacazes (Carvalho et al. 2006). Entretanto, no Estado do Espírito Santo, esta espécie também destacou-se pelo elevado VI em Cachoeiro de Itapemirim, na FLONA de Pacotuba e na RPPN Cafundó (K.M.P.A. Archanjo, dados não publicados). Neste contexto, é provável que esta espécie seja muito peculiar às referidas regiões.

Verifica-se que quando são consideradas as 10 primeiras espécies em termos de valor de importância ocorre um domínio de grupos iniciais (PI e SI) na comunidade da BHRSD, pois foram constatadas apenas três secundárias tardias entre estas espécies. Embora a deciduidade periódica das FES possa favorecer as espécies secundárias iniciais, o destaque deste grupo sucessional parece estar mais relacionado a perturbações antrópicas no ambiente (Fonseca \& Rodrigues 2000).

Se comparada a outras FES no sudeste do Brasil, a porcentagem de espécies caracterizadas pela síndrome zoocórica $(56,8 \%)$, na comunidade estudada, foi baixa, porém, próxima ao limite inferior registrado tanto para área perturbada $(61,6 \%)$ (Yamamoto et al. 2007) quanto para preservada $(64,0 \%)$ (Dias-Neto et al. 2009). Das 10 espécies de maior VI na comunidade, apenas duas foram caracterizadas pela síndrome zoocórica de 
dispersão. Este fato parece indicar que apesar desta comunidade, na sua totalidade, apresentar uma expressiva riqueza e diversidade de espécies arbóreas com síndrome zoocórica, atualmente há uma baixa dominância deste grupo com sua composição estrutural alterada. Tabarelli et al. (1999) demonstraram que em florestas atlânticas do sudeste do Brasil existe um declínio de 9\% em média nos fragmentos pequenos da importância relativa de Myrtaceae, Lauraceae, Sapotaceae e Rubiaceae, que são principais famílias provedoras de frutos carnosos aos frugívoros. Assim, mesmo estando estas famílias entre as mais ricas em espécies neste levantamento, verifica-se que as mesmas não estiveram representadas entre as espécies de maior valor de importância na BHRSD, o que sugere que as espécies destas famílias provavelmente estão em processo de substituição na comunidade por outras mais adaptadas aos ambientes perturbados. De fato, quando consideradas as cinco áreas amostrais deste trabalho verifica-se que, entre todos, apenas no fragmento EMB foi registrado a presença de uma espécie de Sapotaceae, Chrysophyllum gonocarpum, entre as 10 com maior valor de cobertura.

Além disso, de acordo com Tabarelli et al. (2004), as regiões florestais mais fragmentadas perderam ou irão perder uma parte importante de sua diversidade arbórea, em função de distúrbios ambientais tais como corte seletivo de madeira, caça, aumento na ocorrência de queimadas e invasão de lianas e espécies ruderais. Neste sentido, entre as espécies madeiráveis de alto valor comercial que foram apontadas pelos moradores locais da BHRSD como abundantes, no passado, e que foram muito visadas para corte estiveram Paratecoma peroba (peroba-amarela), Cariniana estrellensis (jequitibá), Aspidosperma sp.1 (peroba-rosa) e Myrocarpus frondosus (óleovermelho) que, em nossa amostragem, foram representadas por um único indivíduo cada. Além disso, a maioria das espécies apresentaram indivíduos de pequeno porte, indicando que estas populações foram muito reduzidas.

Por outro lado, como poderiam estes fragmentos florestais ainda ter uma riqueza e diversidade de espécies tão alta apesar de todas as características de áreas perturbadas apresentadas pelos trechos florestais amostrados? É notável que a região noroeste fluminense, onde está inserida a BHRSD, está localizada na transição geográfica entre os dois principais corredores de biodiversidade da Mata Atlântica (s.l.), o Corredor Central, ao norte, e o Corredor da Serra do Mar, ao sul (Ayres et al. 2005). Esta região coincide, em sua faixa latitudinal, com a "Falha de Campos dos Goytacazes", que é considerada uma interrupção biogeográfica natural das florestas ombrófilas litorâneas ao norte e ao sul da mesma. Ali existe uma diminuição considerável da umidade desde o sul de São Paulo até o norte do Rio de Janeiro. A partir daí as florestas ombrófilas reaparecem no Espírito Santo, conforme aumenta a pluviosidade média anual e diminui a sazonalidade, alcançando áreas até o sul da Bahia (Oliveira-Filho \& Fontes 2000; Oliveira-Filho et al. 2005). Esta interrupçãoé, em parte, explicada pela corrente oceânica fria de Cabo Frio (Araujo 1997) que favorece as FES a alcançarem o oceano na região norte-fluminense.

Oliveira-Filho \& Fontes (2000) propuseram a classificação de grupos de espécies indicadoras das diferentes fisionomias florestais da Mata Atlântica baseados na associação destas com as diferentes formações florestais, obtidas através de análises multivariadas realizadas com dados provenientes de 125 áreas florestais e 1002 espécies. Sendo assim, verificou-se que as 198 espécies encontradas na BHRSD, quando contextualizadas nos grupos indicadores propostos por Oliveira-Filho \& Fontes (2000), 21 espécies foram consideradas indicadoras da floresta ombrófila de baixa altitude do norte (Corredor Central); cinco espécies indicadoras de floresta ombrófila de baixa altitude do sul (Corredor da Serra do Mar); 15 de floresta estacional semidecidual de baixa altitude do leste; cinco de floresta estacional semidecidual montana e submontana do oeste; 15 consideradas generalistas ou "Supertramp"; e apenas uma associada a floresta estacional e ombrófila de grande altitude (Tab. 5). Todas estas somam apenas 62 espécies $(30,65 \%)$ do total encontrado na BHRSD. Assim, embora este estudo represente uma primeira aproximação da flora arbórea do noroeste fluminense, os resultados indicam que a região possui uma flora arbórea que recebe influência relativamente equilibrada na sua composição específica, numa proporção 20:26 de espécies indicadoras de FES:FOD, que seria considerada alta para qualquer outro trecho na Mata Atlântica. É provável que este fato esteja relacionado à posição geográfica do noroeste fluminense. Ou seja, pela ocorrência da falha de 
Tabela 5 - Lista de espécies apontadas por Oliveira-Filho \& Fontes (2000) como indicadoras para as diversas fisionomias no domínio da Floresta Atlântica do sudeste brasileiro, presentes nos fragmentos de Floresta Estacional Semidecidual Submontana na BHRSD, São José de Ubá, RJ. N = número de total de espécies indicadoras de cada fisionomia.

Table 5 - List of species suggested by Oliveira-Filho \& Fontes (2000) as indicators for the different Atlantic Forest physiognomies in southeastern Brazil, present in fragments of Semideciduous Submontane in BHRSD, San Jose de Uba, RJ, Brazil. N = total number of indicator species of each physiognomy.

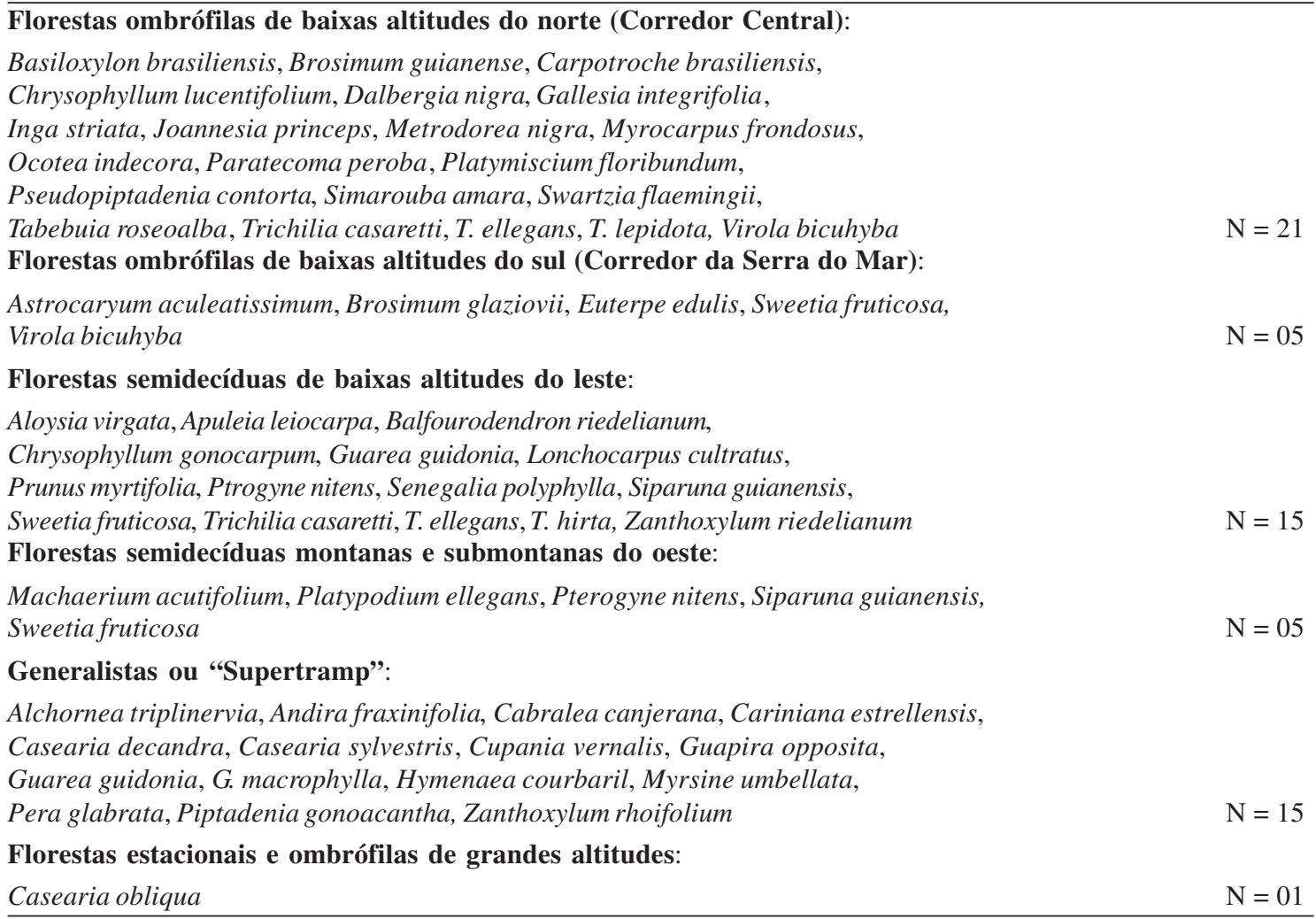

Campos (Oliveira-Filho \& Fontes 2000), que representa uma faixa relativamente pequena dentro de um continuum de FOD.

A ocorrência de espécies raras e/ou ameaçadas de extinção na comunidade arbórea de fragmentos da BHRSD indica a necessidade emergente de conservação destes remanescentes florestais que, apesar dos impactos antrópicos já relatados, apresentam uma diversidade específica relativamente alta para os padrões do bioma Mata Atântica. Assim, medidas criteriosas devem ser estabelecidas pelos órgãos ambientais competentes do governo para a preservação e restauração dos remanescentes da BHRSD. Entre as possíveis medidas destacamos a criação de uma Unidade de Conservação de proteção integral, conforme salientado em estudo recente (Scarano et al. 2009), o estabelecimento de conectividade entre os fragmentos através de corredores florestais, o enriquecimento com espécies nativas tardias/ zoocóricas nas áreas mais perturbadas (ex. fragmento $\mathrm{CAB}$ ) a proteção contra queimadas, e uma fiscalização permanente nos remanescentes coibindo o corte de árvores e a caça. Sem uma atuação efetiva dos órgãos ambientais e do envolvimento das comunidades locais estas pequenas manchas florestais, em um futuro próximo, deixarão de representar uma importante parcela da biodiversidade da região.

\section{Agradecimentos}

Agradecemos aos pesquisadores do Instituto de Pesquisas do Jardim Botânico do Rio de Janeiro, Alexandre Quinet, Haroldo C. Lima e Ronaldo Marquete, o auxílio na identificação do material botânico; à equipe do herbário UENF, a colaboração na preparação, manutenção e conservação das 
exsicatas, a Ana Paula da Silva, Karla M.P.A. Archanjo e Willian M. Aguiar, o auxílio na análise dos dados; a Gerson R. Purificação, Helmo S. Carvalho, Ana Carolina C. Ribeiro e Tatiane P. Souza, o auxílio nos trabalhos de campo; aos donos das propriedades rurais onde foram realizados os levantamentos, a permissão do livre acesso as áreas; ao Projeto RioRural/GEF, o apoio financeiro; ao LCA/CBB/UENF, SEAPPA e EMATER-RIO, o apoio logístico; ao $\mathrm{CNPq}$, a concessão da bolsa de produção científica a MTN e à FAPERJ programa Mata Atlântica, a concessão da bolsa de mestrado ao primeiro autor. Apoio financeiro: Projeto Rio Rural / GEF.

\section{Referências}

APG II. 2003. An update of the Angiosperm Phylogeny Group classification for the orders \& families of flowering plants: APG II. Botanical Journal of the Linnean Society 141: 399-436.

Araujo, D.S.D. 1997. Mata Atlântica: CPD site SA14, Cabo Frio Region, south-eastern Brazil. In: Davis, S.D.; Heywood, V.H.; Herrera-MacBryde, O.; VillaLobos; J. \& Hamilton, A.C. (eds.). Centers of plant diversity: a guide and strategy for their conservation, World Wildlife Fund and The World Conservation Union, London. Pp. 373-375.

Araújo, F.S.; Martins, S.V.; Meira Neto, J.A.A.; Lani, J.L. \& Pires, I.E. 2006. Estrutura da vegetação arbustivo-arbórea colonizadora de uma área degradada por mineração de caulim, Brás Pires, MG. Revista Árvore 30: 107-116.

Ayres, J.M.; Fonseca, G.A.B.; Rylands, A.B.; Queiroz, H.L.; Pinto, L.P.; Masterson, D. \& Cavalcanti, R.B. 2005. Os corredores ecológicos das florestas tropicais do Brasil. Sociedade Civil Mamirauá, Belém. 256p.

Borém, R.A.T. \& Ramos, D.P. 2001. Estrutura fitossociológica da comunidade arbórea de uma topossequência pouco alterada de uma área de Floresta Atlântica, no município de Silva JardimRJ. Revista Árvore 25: 131-140.

Borém, R.A.T. \& Oliveira-Filho, A.T. 2002. Fitossociologia do estrato arbóreo em uma topossequência alterada de Mata Atlântica, no município de Silva JardimRJ, Brasil. Revista Árvore 26: 727-742.

Brower, J.E. \& Zar, J.H. 1984. Field and laboratory methods for general ecology. W. C. Brown Company Publishers, Iowa. 226p.

Carvalho, F.A.; Braga, J.M.A.; Gomes, J.M.L.; Souza, J.S. \& Nascimento, M.T. 2006. Comunidade arbórea de uma floresta de baixada aluvial no município de Campos dos Goytacazes, RJ. Cerne 12: 157-166.

Carvalho, F.A.; Nascimento; M.T. \& Braga, J.M.A. 2007. Estrutura e composição florística do estrato arbóreo de um remanescente de Mata Atlântica Submontana no município de Rio Bonito, RJ, Brasil (Mata Rio Vermelho). Revista Árvore 31: 717-730.

Carvalho, F.A.; Nascimento, M.T. \& Oliveira Filho, A.T. 2008. Composição, riqueza e heterogeneidade da flora arbórea da bacia do rio São João, RJ, Brasil. Acta Botanica Brasilica 22: 929-940.

Carvalho, F.A.; Braga, J.M.A. \& Nascimento, M.T. 2009. Estrutura da comunidade arbórea de fragmentos de floresta atlântica ombrófila submontana na região de Imbaú. Rodriguésia 60: 695-710.

CONAMA. 1994. Resolução Nº 6, de 04 de Maio de 1994. Biomas - Estágios sucessionais da vegetação da Mata Atlântica. Pp. 179-181.

Dalanesi, P.E.; Oliveira-Filho, A.T. \& Fontes, M.A.L. 2004. Flora e estrutura do componente arbóreo da floresta do Parque Ecológico Quedas do Rio Bonito, Lavras, MG, e correlações entre a distribuição das espécies e variáveis ambientais. Acta Botanica Brasilica 18: 737-757.

Dias-Neto, O.C.; Schiavini, I.; Lopes, S.F.; Vale, V.S.; Gusson, A.E. \& Oliveira, A.P. 2009. Estrutura fitossociológica e grupos ecológicos em fragmento de floresta estacional semidecidual, Uberaba, Minas Gerais, Brasil. Rodriguésia 60: 1087-1100.

Dobzhansky, T. 1950. Evolution in the tropics. American Scientist 38: 209-221.

Fidalgo, E.C.; Uzêda, M.C.; Bergallo, H.G.; Costa, T.C. \& Abreu, M.B. 2009. Distribuição dos remanescentes vegetais do estado do Rio de Janeiro. In: Bergallo, H.G.; Fidalgo, E.C.C.; Rocha, C.F.D.; Uzêda, M.C.; Costa, M.B.; Alves, M.A.S.; Van Sluys, M.; Santos, M.A.; Costa, T.C.C. \& Cozzolino, A.C.R. (eds.). Estratégias e ações para conservação da biodiversidade no estado do Rio de Janeiro. Instituto Biomas \& Secretaria do Estado de Ambiente/Instituto Estadual do Ambiente, Rio de Janeiro. Pp. 91-99.

Fonseca, R.C.B. \& Rodrigues, R.R. 2000. Análise estrutural e aspectos do mosaico sucessional de uma floresta semidecídua em Botucatu, SP. Scientia Forestalis 57: 27-43.

Fundação SOS Mata Atlântica. 2007. Atlas dos municípios da mata atlântica. Disponível em <http://www. sosmatatlantica.org.br/index.php? section $=$ atlas\&action=atlas $>$. Acesso em 31 junho 2007.

Fundação SOS Mata Atlântica \& INPE. 2008. Atlas dos remanescentes florestais da Mata Atlântica no período de 2000-2005: relatório final. Fundação SOS Mata Atlântica/INPE, São Paulo.

Gandolfi, S.; Leitão Filho, H. \& Bezarra, C.L.F. 1995. Levantamento florístico e caráter sucessional das espécies das espécies arbustivo-arbóreas de uma floresta mesófila semidecídua no município de 
Guarulhos - SP. Revista Brasileira de Botânica 55: 753-767.

Gonzaga, A.P.D.; Oliveira-Filho, A.T.; Machado, E.L. M.; Hargreaves, P. \& Machado, J.N.M. 2008. Diagnóstico florístico-estrutural do componente arbóreo da floresta da Serra de São José, Tiradentes, MG, Brasil. Acta Botanica Brasilica 22: 505-520.

Gotelli, N.J. \& Entsminger G.L. 2001. EcoSim: Null models software for ecology. Version 7.0. Acquired Intelligence Inc. \& Kesey-Bear.

IBGE. 1993. Mapa da vegetação do Brasil. Instituto Brasileiro de Geografia e Estatística, Rio de Janeiro.

Kurtz, B.C. \& Araujo, D.S.D. 2000. Composição florística e estrutura do componente arbóreo de um trecho de Mata Atlântica na Estação Ecológica Estadual do Paraíso, Cachoeiras de Macacu, Rio de Janeiro, Brasil. Rodriguésia 51: 69-111.

Leigh Jr., E.G.; Davidar, P.; Dick, C.W; Puyravaud, J.P.; ter Steege, J. \& Wright, S.J. 2004. Why do some tropical forests have so many species of trees? Biotropica 36: 447-473.

Lopes, W.P.; Silva, A.F.; Souza, A.L. \& Meira-Neto, J.A.A. 2002. Estrutura fitossociológica de um trecho de vegetação arbórea no Parque Estadual do Rio Doce - Minas Gerais, Brasil. Acta Botanica Brasilica 16: 443-456.

MMA. 2000. Avaliação e ações prioritárias para a conservação da biodiversidade da mata atlântica e campos sulinos. Ministério do Meio Ambiente, Brasília.

Moreno, M.R.; M.T. Nascimento \& B. Kurtz. 2003. Estrutura e composição florística do estrato arbóreo em duas zonas altitudinais na Mata Atlântica de encosta da região do Imbé, RJ. Acta Botanica Brasilica 17: 371-386.

Mueller-Dombois, D. \& Ellemberg, H. 1974. Aims and methods of vegetation ecology. John Wiley \& Sons, New York. 547p.

Myers, N.; Myttermeier, R.A.; Myttermeier, C.G.; Fonseca, G.A.B. \& Kent, G. 2000. Biodiversity hotsposts for conservation priorities. Nature 403: 853-858.

Nascimento, M.T. \& Proctor, J. 1997. Soil and plant changes across a monodominant rain forest boundary on Maracá Island, Roraima, Brazil. Global Ecology and Biogeograph Letters 6: 387-395.

Nascimento, M.T. \& Lima, H.C. 2008. Floristic and structural relationships of a tabuleiro forest in northeastern Rio de Janeiro, Brazil. In: Thomas, W. (ed.). The Atlantic Coastal Forest - Northeastern Brazil. Memoirs of the New York Botanical Garden 100: 395-416.

Oliveira-Filho, A.T. \& Fontes. M.A.L. 2000. Patterns of floristic differentiation among Atlantic forests in southeastern Brazil, and the influence of climate. Biotropica 32: 793-810.
Oliveira-Filho, A.T.; Tameirão-Neto, E.; Carvalho, W.A.C.; Werneck, M.; Brina, A.E.; Vidal, C.V.; Rezende, S.C. \& Pereira, J.A.A. 2005. Análise florística do compartimento arbóreo de áreas de Floresta Atlântica sensu lato na região das Bacias do Leste (Bahia, Minas Gerais, Espírito Santo e Rio de Janeiro). Rodriguésia 56: 185-235.

Prado, R.B. \& Di Lullo, L.B. 2007. Estudo de índices de qualidade da água na bacia hidrográfica do rio São Domingos - RJ. Boletim de Pesquisa e Desenvolvimento, Embrapa Solos, Rio de Janeiro. 54p.

Putz, F.E. \& Mooney, H. A. 1991. The biology of vines. Cambridge University Press. New York. 526p.

RioRural-GEF. 2007. Marco zero: sub-componente monitoramento e avaliação. Relatório Técnico. RioRural-GEF, Rio de Janeiro. 59p.

Scarano, F.R. 2002. Structure, function and floristic relantioships of plants communities in stressful habitats marginal to Brazilian Atlantic Rainforest. Annals of Botany 90: 517-524.

Scarano, F.R.; Costa, D.P.; Freitas, L.; Lima, H.C.; Martinelli, G.; Nascimento, M.T.; Sá, C.F.C.; Salgueiro, F.; Araujo, D.S.D. \& Raíces, D.S.L. 2009. Conservação da flora do Estado do Rio de Janeiro: até onde a ciência pode ajudar. In: Bergallo, H.G.; Fidalgo, E.C.C.; Rocha, C.F.D.; Uzêda, M.C.; Costa, M.B.; Alves, M.A.S.; Van Sluys, M.; Santos, M. A.; Costa, T.C.C. \& Cozzolino, A.C.R. (eds.). Estratégias e ações para conservação da biodiversidade no estado do Rio de Janeiro. Instituto Biomas \& Secretaria do Estado de Ambiente/Instituto Estadual do Ambiente, Rio de Janeiro. Pp. 221-233.

Schilling, A.C. \& Batista, J.L.F. 2008. Curva de acumulação de espécies e suficiência amostral em florestas tropicais. Revista Brasileira de Botânica 31: 179-187.

Scudeller, V.V.; Martins, F.R. \& Shepherd G.J. 2001. Distribution and abundance of arboreal species in the atlantic ombrophilous dense forest in Southeastern Brazil. Plant Ecology 152: 185-199.

Shepherd, G.J. 1995. FITOPAC 1: manual do usuário. UNICAMP, Departamento de Botânica, Campinas.

Silva, G.C. \& Nascimento, M.T. 2001. Fitossociologia de um remanescente de mata sobre tabuleiros no norte do estado do Rio de Janeiro (Mata do Carvão). Revista Brasileira de Botânica 24: 51-62.

Silva, V.F.; Venturin, N.; Oliveira-Filho, A.T.; Macedo, R.L.G.; Carvalho, A.C. \& Berg, E.V.D. 2003. Caracterização estrutural de um fragmento de floresta semidecídua no município de Ibituruna, MG. Cerne 91: 92-106.

Tabarelli, M.; Mantovani, W. \& Peres, C.A. 1999. Effects of habitat fragmentation on plant guild structure in the montane Atlantic forest of southeastern Brazil. Biological Conservation 91: 119-127. 
Tabarelli, M.; Silva, J.M.C. \& Gascon, C. 2004. Forest fragmentation, synergisms and the impoverishment of neotropical forests. Biodiversity and Conservation 13: 1419-1425.

Thomaz, L.D.; Monteiro, R. 1997. Composição florística da mata atlântica de encosta da estação Biológica de Santa Lúcia, município de Santa Tereza-ES. Boletim do Museu de Biologia Mello Leitão 7: 3-48.
Van der Pijl, L. 1982. Principles of dispersal in higher plants. 3rd ed. Springer-Verlag, Berlin. 197p.

Weaver, J.E. \& Clements F.E. 1938. Plant ecology. $2^{\mathrm{a}}$ ed. McGraw-Hill Book Company, New York. 601p.

Yamamoto, L.F.; Kinoshita, L.S. \& Martins, F.R. 2007. Síndromes de polinização e de dispersão em fragmentos da Floresta Estacional Semidecídua Montana, SP, Brasil. Acta Botanica Brasilica 21: 553-573. 